Please quote as: Bretschneider, U.; Rajagopalan, B. \& Leimeister, J. M. (2012): Idea Generation in Virtual Communities for Innovation: The Influence of Participants' Motivation on Idea Quality. In: 45. Annual Hawaii International Conference on System Sciences (HICSS), Grand Wailea, Maui. 


\section{Idea Generation in Virtual Communities for Innovation: The Influence of Participants' Motivation on Idea Quality}

\author{
Ulrich Bretschneider \\ Information Systems \\ Kassel University \\ bretschneider@uni-kassel.de
}

\author{
Balaji Rajagopalan \\ School of Business Administration \\ Oakland University \\ rajagopa@oakland.edu
}

\author{
Jan Marco Leimeister \\ Information Systems \\ Kassel University \\ leimeister@uni-kassel.de
}

\begin{abstract}
Virtual Communities for Innovations (VCI) are becoming increasingly popular as platforms for firms to engage customers in generating new ideas. While several studies have explored the various motivations of user participation in VCI, the relationship between the motivations and the outcome of interest - the quality of the ideas - has not been explored. Scholars and practitioners have a strong interest in understanding the influence of motivation on quality of ideas. These as valuable insights will help firms who run VCI and are interested in harvesting ideas of good quality from it create effective incentive strategies for generating good ideas. In our research, we hypothesize that certain motivations influence idea quality, while others do not. We find empirical support for the following motivations influencing idea quality: (1) demonstrate personal capabilities and skills through their ideas (capability signaling-motive); (2) get recognition of third parties through their ideas (recognition-motive); and (3) have fun in developing ideas (fun-motive). However, we find no evidence for the influence of customers' altruism (altruism-motive), nor of customers' desire for improving and enhancing existing firms' products by submitting ideas (Product Improvement and Enhancement-motive).
\end{abstract}

\section{Introduction}

Idea generating platforms, such as DELL's Ideastorm (www.ideastorm.com) have transformed the process of how firms' innovations have germinated and developed. Such communities, where distributed groups of individual customers and product users ${ }^{1}$ focus on voluntarily sharing and elaborating new ideas, are used by firms as a promising practice for transcending their boundaries in search of innovation

\footnotetext{
${ }^{1}$ In some cases it is better to speak of product users instead of customers. For example, in the case of the software producer, SAP, the ones who "buy" the software are typically not the ones who use this software. Regarding the backdrop of the here discussed Open Innovation paradigm, both terms can be used synonymously, which we do in the rest of this paper.
}

according to Chesbrough's Open Innovation paradigm [11]. Companies such as Google, Intel, BMW, SAP, and Acrobat are a few examples that run idea communities.

In many instances, customers are seen as one of the key resources for idea generation, as they often have deep product knowledge as well as experience and creativity potential gained by regular product usage. Ideas generated by customers typically reflect their needs and wishes but may also represent suggestions describing how ideas can be transferred into marketable products.

We characterize Virtual Communities for Innovations (VCI) as having the following features: (1) They are communities - which implies that the members share a common goal, may be open or closed membership, and interact online significantly. (2) One of the main purposes of the community is to generate ideas, (3) All participants in the community have access to all ideas generated (transparency), (4) All participants of the community should be able to provide feedback on the ideas generated.

There is evidence that customers participate in VCI not only to establish and maintain contact with other customers, such as social support, friendship, and intimacy, but for several other reasons. First, there is the need-motive. Customers feel that by participating in VCI they can influence the firm to incorporate certain product features that are highly valuable in the customers' application context [9]. Second, by contributing ideas customers wish to accentuate the necessity of improving the functionality or a defect of the underlying product (product improvement motive) $[9,32]$. Next, there is the learning-motive. Very often customers engage in a firm's ideation within VCI as well as in non-online ideation, such as lead user workshops and focus groups, to gain knowledge from participating in VCI $[9,32]$. Such customer involvement enhances customers' knowledge about the product, as well as about the underlying technologies. This, in turn, enables them to use the product in a much more comprehensive manner, thereby increasing the potential benefit of product usage [39]. Customers 
participate in VCI to satisfy their creative urge and product-related curiosity (fun-motive) [9]. Further, they find developing ideas to be intellectually stimulating (intellectual stimulation motive) [9]. Additionally, Bretschneider [9] found that customers participate in VCI's ideation processes not only because they feel a sense of obligation to give something back to the firm in return for the products it provides (reciprocity motive), but also because they feel aligned to the firm (identifying-with-the-firm motive).

While several studies have explored the various motivations of user participation in VCI, the relationship between the motivations and the outcomes of interest (ideas generated, quality of ideas) has not been explored. Scholars and practitioners share a strong interest in understanding the influence of motivation on creativity. From a scientific perspective, there are calls to clarify dependency between motivation and creativity [20, 46], as science needs new theoretical perspectives and empirical investigations to deepen knowledge of the motivational processes that drive creativity [46]. But there is also a need to research this from a practical perspective. Knowing which motives impact customers' creativity will provide valuable insights into how firms - who run VCI and are interested in harvesting ideas of good quality from it - can create effective incentive strategies to attract customers to generate high quality ideas. Thus, our focus in this study is to examine the influence of different motives on idea quality. Using the "SAPiens" VCI as the context, we empirically study a range of motives that drive participants of SAPiens to submit ideas.

\section{Theoretical Background: Intrinsic and Extrinsic Motivation}

Psychologists distinguish between intrinsic and extrinsic motivation $[15,28]$. The former refers to the desire to feel competent and self-determined. Extrinsic motivation includes rewards such as direct or indirect monetary compensation and recognition by others. The distinction between motivations rooted in the psychology of the individual (internal factors) and motivations that originate from the environment (external factors, rewards) will be used as the basis for discussing further motivation factors that generally lead individuals to participate in virtual communities, and thus, are relevant to our research.

Human motivations for participation in virtual communities have been studied by psychologists in a variety of contexts. In general, motivations of participants of different virtual communities vary, depending on the type of community. These motivations are based, for example, on whether the community was centered on tightly coupled ties in a small group or loosely coupled ties between users in a larger network based on shared interest.

For example, a very prominent motive is peer to peer communication. This is related to keeping in contact with other people for social support and friendship. The peer to peer communication-motive was found to be highly relevant in several contexts, particularly in virtual communities for patients as patients' need for emotional support from peers is very intense [33].

The recognition-motive has been studied in several open source motivation studies. Hars and $\mathrm{Ou}$ [25] found that programmers engage in Open Source communities because they hope to receive positive reaction about their submitted program codes from other programmers. Applied to VCI participants expect positive reactions from other participants as well as from the organizer. These reactions by third parties may be triggered by the submitted ideas displayed on the Internet platform.

Another motive is "altruism" that has been studied in the context of open source communities [25], virtual communities for patients, as well as the Wikipedia community. For example, open source software programmers who are motivated by altruism seek to increase the welfare of the open software community by writing program codes without expecting any reward. Rafaeli et al. [44] looked at motivations that contribute to Wikipedia. They found that most Wikipedians contribute because of their altruistic attitudes. Altruism can also be presumed to be a driver that motivates customers to participate in VCI.

Furthermore, people may consider participating in virtual communities as an effective way to demonstrate their capabilities and skills shown through their contributions. Their achievements in virtual communities can be used to demonstrate competence to the organizer of the ideas community or other participants. Thus, participating can be a good channel for self-advertisement. This capability signalingmotive is mainly discussed in the field of researching motivations of open source programmers [25] as well as in the mentioned Wikipedia motivation study by Rafaeli et al. [44]. Table 1 summarizes the various motivational factors discussed.

Table 1. Extrinsic and intrinsic motivations

\begin{tabular}{ll}
\hline Intrinsic Motivations & Extrinsic Motivations \\
\hline Peer to peer communication & Recognition \\
\hline Altruism & Capability signaling \\
\hline Identifying with the firm & Learning \\
\hline Reciprocity & \\
\hline
\end{tabular}




\begin{tabular}{l}
\hline Intellectual stimulation \\
\hline Fun \\
\hline Product improvement \\
\hline Need \\
\hline
\end{tabular}

\section{Data and Measures}

Data were gathered from www.sapiens.info (SAPiens). SAPiens is a Virtual Community for Innovation (VCI) initiated and run by the ERP software developer, SAP. SAPiens was launched in the summer of 2009 and targeted users of SAP software. Our survey sought to explore the motives that encourage users of SAP software to submit ideas to SAPiens. Since perceived motivation-related issues can best be expressed by participants of the SAPiens community themselves, we conducted a standardized questionnaire survey. There were 29 items formulated in order to measure the eleven motives discussed in the previous sections (see Table 1).

Using a Likert rating scale ranging from 1 (strongly disagree) to 5 (strongly agree), participants were asked to rate the degree to which each motive motivated them to participate. The questionnaire used in this study was structured, tested, and consequently adapted to the needs of the target audience. The questionnaire was pre-tested by ten experts pursuing doctoral and Master's degrees in information technology and business administration. The objectives of the pre-test were to ensure that none of the items were ambiguous and to confirm that the items adequately captured the domain of interest. Expert opinions indicated that the content of the items had face validity.

We conducted the online survey in March 2010. The questionnaire was implemented using an onlinesurvey service. Participants of SAPiens VCI who submitted at least one idea were provided with a personalized link to the online survey by e-mail. The survey was administered over a period of four weeks. A total of 87 participants provided usable responses to the questionnaire representing a $58.39 \%$ response rate. Of the 87 responses, $70.11 \%$ were men $(n=61)$, and $60.92 \%(n=53)$ were between 20 and 30 years old. Concerning the occupation of the participants, $55.17 \%$ $(n=48)$ were students who were overrepresented in the sample. The rest were either SAP consultants or professionals working with SAP applications.

The high number of students is not unusual, as the community managers of the SAPiens community recruit many different kinds of SAP users, including students of higher education. However, students are only allowed to take part in the SAPiens community if they can verify degrees from so called "TERP 10" courses, i.e., advanced SAP training courses for students of higher education that train students in handling SAP software and that are certified and supported by SAP. Because of this, we could be certain of students' SAP expertise.

\section{Instrument Validity}

We tested construct validity of our 11 motives and related 29 items based on an exploratory factor analysis. In order to check whether the data were appropriate for factor analysis, we pre-analyzed the Measures of Sampling Adequacy (MSA) for the whole data structure as well as for individual items (see Table 7). As shown in Table 7 , items $4.2 ; 8.2 ; 2.1 ; 4.4$, as well as 4.3, showed MSA values that were lower than 0.5. According to Cureton and D'Agostion's recommendation, who deemed that items achieve sampling adequacy if MSA values are equal to or exceed the criterion of 0.5 [13], these items were excluded within six iterations. After the sixth iteration, all remaining items had MSA values above 0.6 making exploratory factor analysis appropriate. Furthermore, we pre-checked the global MSA value after the sixth iteration in order to ensure applicability of exploratory factor analysis. With an MSA of 0.729, Cureton and D'Agostion's [13] stringent 0.5 criteria was also met.

The factor analysis resulted in six factors with eigenvalues higher than 1 (varimax rotation). All six factors taken together explain a total of $66.321 \%$ variance. The first factor explained $14.149 \%$ variance, mostly determined by all items that represent the capability signaling motive as well as item 11.1. The intention to seek peers in order to get in contact can be seen as an assumption for capability signaling activities. As peers constitute the target audience of these activities, the 11.1 loading on this factor can be plausibly accepted. Because of this, we call this factor "capability signaling" (see component 1 in Table 7). The second factor explains $13.887 \%$ variance, mostly determined by "fun" items. Item 2.2 also loads on this factor, and as intellectual stimulation can be interpreted as a form of fun, we accept the inclusion of this item in factor 2. Following this argumentation, we call this factor "fun" (component 2 Table 7).

Items 3.1 and 3.2, as well as 7.2, load on another factor, explaining $11.066 \%$ variance. As altruistic feelings will only be brought toward a certain person (or organization) with whom (or which) one can identify, this seems plausible. Thus, the third factor can be called "altruism" (component 3 in Table 7). On the fourth factor load, three expected items solely explain "recognition" (component 4 in Table 7), (10.040\% variance). 
The fifth factor, which represents a 9.989\% expression of variance, we call "product improvement and enhancement" (component 5 in Table 7) as all needed items, as well as one of two product improvement items, load on it. Finally, the sixth factor which explains additional $7.190 \%$ variance is mostly determined by the supposed learning items. As supposed, learning (component 6 in Table 7) seems to be an independent motive.

The items 4.1, 5.2, 7.1, as well as 11.2 , were excluded as their values were $>0.55$, according to Hair et al.'s recommendation, which deemed that items achieve acceptable factor loadings if values are equal to or exceed the criterion of 0.55 [24]. After this complex exploratory factor analysis, the results support the contention that our model has adequate construct validity.

The reliability of the resulting factors was checked using Cronbach's alpha. A Cronbach's alpha of 0.7 or higher [40] was used as an acceptable value for internal consistency of the measure. The Cronbach's alphas of the four factors range from 0.772 to 0.860 (see Table 2). These values support the contention that all factors had adequate reliability.

As examination of validity and reliability of an underlying research model by solely applying exploratory factor analysis (respectively, Cronbach's alpha) does not meet modern requirements [7], according to Homburg and Giering's recommendation [30], we then tested our new model, based on its six remaining factors and its corresponding 20 items, by applying confirmatory factor analysis and using Amos 18.0. First, we checked the global fit of the new model. The Goodness of Fit Index (GFI) was 0.951, and the Adjusted Goodness of Fit Index (AGFI) was 0.933. These indices were well over the threshold of 0.9 , which indicates an adequate fit [10]. In order to check the reliability of the model, we measured all Individual Item Reliabilities, which exceeded the minimum threshold of 0.4 [30]. Hence, good reliability is confirmed (see Table 2).
Table 2. Individual Item Reliability, Composite Reliability, and AVE

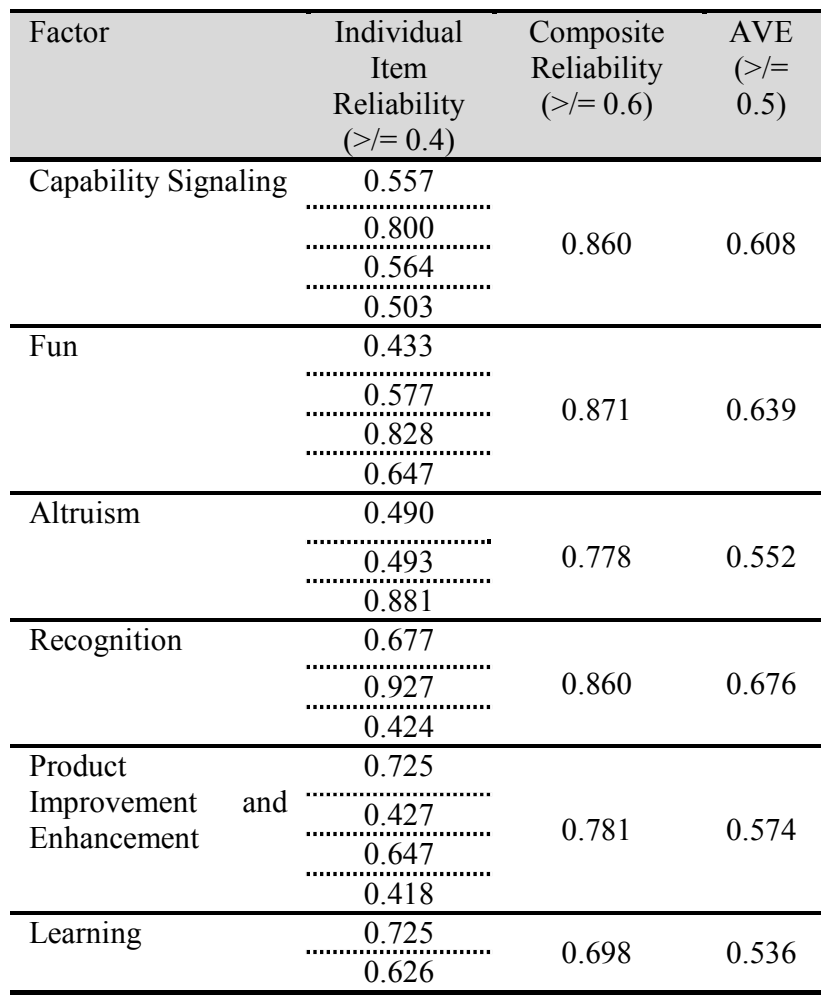

Furthermore, all factors of our new model showed good values for Composite Reliabilities as well as good values for Average Variance Explained (AVE), and thus convergent validity can be assumed (see Table 2). Values of 0.6 for Composite Reliability and 0.5 for the AVE can be seen as minimum values for indicating a good measurement quality [3].

The discriminant validity of the factors was checked by using the Fornell-Larcker criteria, which specifies that a factor's AVE should be higher than its squared correlation with every other factor [18]. Tables 2 and 3 show discriminant validity for the six factors of our new model. Our model is thus successfully validated using both exploratory and confirmatory factor analysis.

Table 3. Squared Multiple Correlations

\begin{tabular}{lcccccc}
\hline & $\begin{array}{c}\text { Capability } \\
\text { signaling }\end{array}$ & Fun & Altruism & Recognition & Prod Imp+ Enh & Learning \\
\hline Capability signaling & & 0.00289 & 0.0729 & 0.2401 & 0.0729 & 0.2704 \\
\hline Fun & 0.0289 & & 0.0324 & 0.0225 & 0.00289 & 0.0324 \\
\hline Altruism & 0.0729 & 0.0324 & & 0.0729 & 0.1156 & 0.1444 \\
\hline Recognition & 0.2401 & 0.0225 & 0.0729 & & 0.1089 & 0.2116 \\
\hline Prod Im + Enh & 0.0729 & 0.00289 & 0.1156 & 0.1089 & & 0.0441 \\
\hline
\end{tabular}




\begin{tabular}{llllll}
\hline Learning & 0.2704 & 0.0324 & 0.1444 & 0.2116 & 0.0441 \\
\hline
\end{tabular}

In order to identify the accumulated parameter values for the new factors which indicate participants' perceived relevance concerning each of these motives, we computed (non-weighted) means of each factors' corresponding item. According to Bortz and Döring [8], it is feasible to calculate accumulated means for each factor by simply adding up the non-weighted ones if factor loadings are homogeneous. As the bold values in the Rotated Component Matrix (see Table 7) indicate, factor loadings fulfill this condition. The Rotated Component Matrix (see Table 7) shows accumulated means that needs to be interpreted in the light of the above mentioned rating scale, ranging from 1 (strongly disagree) to 5 (strongly agree).

\section{Hypotheses Development}

As mentioned, attendants of the SAPiens VCI may consider participation as an effective way of demonstrating their capabilities and skills through their submitted ideas. Therefore, submitted ideas can function as a good channel for demonstrating competences, etc. Since reactions by third parties may be triggered only if ideas of these participants hold a certain quality level, this group will likely be interested in submitting high quality ideas. This leads to our first hypothesis:

H1: Higher levels of capability signaling by participants will have a significant positive influence on the quality of ideas.

Fun has been shown to be a relevant motive of some participants of VCI, suggesting that the creative practice of developing ideas per se is perceived as fun. The research field of creativity gives two featured reasons for this. First, in order to resolve a creative task, there is no pretended ultimate approach [1], and one can decide oneself how to solve that task. Second, the inherent challenge of deciding how to solve the underlying task leads to people having fun in developing ideas [1]. Thus, one can suppose that being creative (in our case, developing ideas) is used by some VCI participants as a way of expressing oneself and for self-actualization, which, in turn, will likely have an impact on the result of this creative process, namely, the idea quality.

H2: Higher levels of fun motivation in participants will have a significant positive influence on the quality of ideas.
Participants of the SAPiens VCI who are motivated by altruism seek to increase the welfare of the SAP users by submitting ideas without expecting any rewards. In general, altruism can be interpreted as the direct opposite to selfishness or as "doing something for another at some cost to oneself" [41]. Thus, in the first instance, participants motivated by altruism seek to do good deeds. Because of this, one can suppose that this motivation will likely not impact the quality of ideas.

H3: Levels of altruism motivation in participation will have no significant influence on the quality of ideas.

In general, recognition is found to be a basic human need, as it gives people a sense of self-esteem $[29,35]$. In our case, participants could receive appreciation on the basis of submitted ideas. Probably, the better the quality of an idea the more appreciation its submitter will receive. In our context, it is thus likely that idea quality depends on recognition.

H4: Higher levels of recognition motivation in participants will have a significant positive influence on the quality of ideas.

Some participants are motivated to submit an idea because they have detected a certain need for product improvement or enhancement that existing SAP software products do not cover. There is an inherent novelty aspect in the motivation factor "need" that is also manifested in the idea quality construct. Because of this, the motivation factor "product improvement and enhancement" will most likely affect idea quality.

H5: Higher levels of product improvement and enhancement motivation for participation will have a significant positive influence on the quality of ideas.

Some members of the SAPiens VCI were motivated to participate in order to expand their personal skills, capabilities, and knowledge. However, these factors are the requirements that are needed to develop ideas of good quality [23]. Thus, the willingness to learn will probably not affect idea quality. This leads to our final hypothesis:

H6: Levels of learning motivation in participants will have no significant influence on the quality of ideas. 


\section{Analyses and Results}

\subsection{Measuring Idea Quality}

In recent years, the research field of creativity has addressed the aspects of idea generation and evaluation [1]. Research efforts that focus on idea evaluation cover the evaluation process as well as the scales for idea evaluation. In the following section, we address both aspects in order to describe how we measured the idea quality of the SAPiens ideas community.

6.1.1 Scale for idea evaluation. Idea quality is a complex construct. Various metrics consisting of different dimensions for assessing the quality of creative ideas have been discussed in the literature. In order to develop a reliable scale, we look to work done in creativity research.

We conducted an extensive literature review and identified 18 articles from creativity research. These papers were useful for our research for the following reasons. First, all of these papers dealt with empirical evaluation of idea quality. Second, all papers had in common that they used a certain scale for evaluating ideas. Accordingly, we carefully analyzed the scales for idea evaluation, particularly the used dimensions of idea quality, in order to check which dimensions did exist and which were appropriable for the development of our own metric. Based on the insights of this research, we used eight dimensions, briefly described as follows.

The first idea dimension is novelty, which is a key criteria when evaluating ideas, e.g., used by Binnewies et al. [6]. An idea is described most novel if - from the perspective of its contemplator - it is rare and nobody has previously expressed it [34]. We adapted novelty unvaried in our scale. Originality is another dimension discussed in evaluating ideas. An original idea is defined consistently as an idea that has the characteristic of being inconvenient, visionary, and surprising [14]. Some authors speak of unusualness [38], creativity [6, 31, 43], or even non-obviousness [34] in terms of originality. We adopted this criterion as originality. Another attribute of idea quality, which we adopted unmodified, is paradigm relatedness. This refers to an idea's transformational character, and describes the degree to which an idea helps to overcome established structures, i.e., how radical or revolutionary it is $[14,19,27]$.

Further, we considered feasibility - also named as "workability," "implementable," or "practicable" - in our scale. In general, in all analyzed articles an idea is considered feasible if it is implementable, e.g., [43]. We adopted this criterion in a modified and twofold way. We considered not only "technical feasibility," which refers to the question of whether or not the underlying idea can be transformed into a commercial product concerning SAP's given capabilities as well as resource, but also "economic feasibility" referring to the question of whether or not an underlying idea can be implemented into a product within an acceptable budget.

Cooper et al. [12] and Dean et al. [14] use acceptability in order to express the degree to which an idea is socially, legally, or politically accepted by others. We adopted acceptability in terms of user acceptance. With this criterion, we measure the degree to which other SAP users deem an idea to be useful. Effectiveness describes the degree to which an idea will solve a problem, e.g., $[4,53]$. As this criterion is useful for our idea scale in the stated manner, we adopted it unmodified. Another trait of idea quality is elaboration, which can be seen as the extent to which an idea is complete, detailed, and well understandable [14]. We adopted this criterion unmodified for our scale.

In the next step, we operationalize each of the idea quality's distinct dimensions by one item (see Table 4).

Table 4. Scale for idea evaluation

\begin{tabular}{|c|c|c|}
\hline Dimension & $\begin{array}{l}\text { Corresponding } \\
\text { item }\end{array}$ & Notice and reference \\
\hline Novelty & $\begin{array}{l}\text { The degree to } \\
\text { which the idea } \\
\text { is rare to SAP } \\
\text { and not } \\
\text { expressed in an } \\
\text { SAP context } \\
\text { before. }\end{array}$ & $\begin{array}{l}\text { Contextualized from } \\
\text { the novelty construct } \\
\text { by } \\
\text { Binneweis/Ohly/Niess } \\
\text { en [6], } \\
\text { Eisenberger/Rhoades } \\
\text { [16], Garfield et al. } \\
\text { [19], } \\
\text { MacCrimmon/Wagner } \\
\text { [34], Massetti [36], } \\
\text { Miura/Hida [37], } \\
\text { Mumford [38], and } \\
\text { Shalley [45]. }\end{array}$ \\
\hline Originality & $\begin{array}{l}\text { The degree to } \\
\text { which the idea } \\
\text { inconvenient, } \\
\text { visionary, and } \\
\text { surprising. }\end{array}$ & $\begin{array}{l}\text { Contextualized from } \\
\text { the originality } \\
\text { construct by } \\
\text { Barki/Pinsonneault } \\
\text { [4], } \\
\text { Binneweis/Ohly/Niess } \\
\text { en [6], Dean et al. } \\
\text { [14], Faure [17], } \\
\text { Hender et al. [27], } \\
\text { Kramer/Kuo [31], } \\
\text { MacCrimmon/Wagner } \\
\text { [34], Miura/Hida [37], } \\
\text { Mumford [38], } \\
\text { Potter/Balthazard } \\
\text { [43], and } \\
\text { Sosik/Avolio/Kahai } \\
\text { [47]. }\end{array}$ \\
\hline
\end{tabular}




\begin{tabular}{|c|c|c|}
\hline $\begin{array}{l}\text { Paradigm } \\
\text { relatedness }\end{array}$ & $\begin{array}{l}\text { The degree to } \\
\text { which the idea } \\
\text { helps to } \\
\text { overcome } \\
\text { established } \\
\text { SAP structures, } \\
\text { and is radical } \\
\text { and } \\
\text { revolutionary } \\
\text { form SAP's } \\
\text { point of view. }\end{array}$ & $\begin{array}{l}\text { Contextualized from } \\
\text { the paradigm } \\
\text { relatedness construct } \\
\text { by Dean et al. [14], } \\
\text { Garfield et al. [19], } \\
\text { and Hender et al. [27]. }\end{array}$ \\
\hline $\begin{array}{l}\text { Technical } \\
\text { feasibility }\end{array}$ & $\begin{array}{l}\text { The degree to } \\
\text { which SAP can } \\
\text { implement the } \\
\text { idea } \\
\text { concerning } \\
\text { SAP's } \\
\text { capabilities and } \\
\text { resource. }\end{array}$ & \multirow{2}{*}{$\begin{array}{l}\text { Developed in this } \\
\text { research by building } \\
\text { on the feasibility } \\
\text { construct by } \\
\text { Barki/Pinsonneault } \\
\text { [4], Dean et al. [14], } \\
\text { Faure [17], } \\
\text { Kramer/Kuo [31], } \\
\text { MacCrimmon/Wagner } \\
\text { [34], Mumford [38], } \\
\text { Potter/Balthazard } \\
\text { [43], Straus/McGrath } \\
\text { [49], and Valacich et } \\
\text { al. [53] who } \\
\text { considered feasibility } \\
\text { originally as the } \\
\text { degree to which an } \\
\text { idea can be easily } \\
\text { implemented. }\end{array}$} \\
\hline $\begin{array}{l}\text { Economic } \\
\text { feasibility }\end{array}$ & $\begin{array}{l}\text { The degree to } \\
\text { which SAP can } \\
\text { implement the } \\
\text { idea to an } \\
\text { acceptable } \\
\text { budget. }\end{array}$ & \\
\hline Acceptability & $\begin{array}{l}\text { The degree to } \\
\text { which SAP } \\
\text { users will deem } \\
\text { the idea as } \\
\text { useful. }\end{array}$ & $\begin{array}{l}\text { Developed in this } \\
\text { research by building } \\
\text { on the construct by } \\
\text { Cooper et al. [12] and } \\
\text { Dean et al. [14] who } \\
\text { considered } \\
\text { acceptability } \\
\text { originally as the } \\
\text { degree to which an } \\
\text { idea is socially, } \\
\text { legally, and/or } \\
\text { politically accepted. }\end{array}$ \\
\hline Effectiveness & $\begin{array}{l}\text { The degree to } \\
\text { which an idea } \\
\text { will solve a } \\
\text { problem in the } \\
\text { SAP context. }\end{array}$ & $\begin{array}{l}\text { Contextualized from } \\
\text { the constructs by } \\
\text { Barki/Pinsonneault } \\
\text { [4], Dean et al. [14], } \\
\text { Faure [17], and } \\
\text { Kramer/Kuo [31]. }\end{array}$ \\
\hline Elaboration & $\begin{array}{l}\text { The degree to } \\
\text { which the idea } \\
\text { is complete, } \\
\text { detailed and } \\
\text { well } \\
\text { understandable. }\end{array}$ & $\begin{array}{l}\text { Contextualized and } \\
\text { renamed from the } \\
\text { constructs by Dean et } \\
\text { al. [14] and } \\
\text { MacCrimmon/Wagner } \\
{[34] \text {. }}\end{array}$ \\
\hline
\end{tabular}

6.1.2 Assessing idea quality. Due to the "fuzziness" of the idea construct, a broad range of different evaluation methods for assessing idea quality is discussed in the literature and applied in practice. In general, the evaluation process is carried out by an independent expert jury, but the methods in use range from unstructured discussions to complex rating schemes based on consensual assessments of the referees [42]. Based on our evaluation scale, we evaluated 61 ideas using Amabile's Consensual Assessment Technique (CAT) [1], which has been extensively used for evaluating customer generated new product ideas. We selected ideas that were submitted by the 87 SAPiens community members that were considered in the above-mentioned motivation survey. As 26 submitted ideas were inappropriate for idea evaluation, these ideas were excluded from assessment.

Using the CAT method, the remaining 61 ideas were evaluated by a jury consisting of experts in the domain of SAP. In our case, the jury consisted of six referees, who were employees of either SAP or the German SAP University Competence Centers. For evaluation, each idea description was pasted into separate evaluation forms, which also contained the scales for idea evaluation. Thus, 61 evaluation forms were handed out to each referee in a randomized order. All judges were assigned to rating the ideas with the eight different items on a rating scale ranging from 1 (lowest) to 5 (highest). Each member of the jury evaluated the ideas independent of the others.

According to Amabile [1], reliability of an scale that is used in the scope of Amabile's CAT is good if all judges of the jury evaluate the ideas concerning each dimension almost equal. That means that ratings on each dimensions should be analyzed for inter-judge reliability [1]. We checked the inter-rater reliability for our case by calculating Intra-Class-Correlation (ICC) coefficients. According to Amabile, ICC coefficients have to be higher than or equal to 0.7 in order to indicate a sufficient degree of inter-rater reliability [1]. In our case, most ICC coefficients were $>0.7$, but some values failed to meet this required minimum (see Table 5). As these values were only slightly below the required minimum (or at least in an acceptable tolerance range) and since our study is exploratory in nature, we deemed reliability of our results to be acceptable [24].

Table 5. ICC-coefficients for idea dimensions

\begin{tabular}{lc}
\hline Item & ICC-Coefficient \\
\hline Novelty & 0.708 \\
\hline Originality & 0.834 \\
\hline Paradigm relatedness & 0.746 \\
\hline Technical feasibility & 0.621 \\
\hline Economic feasibility & 0.599 \\
\hline Acceptability & 0.654 \\
\hline Effectiveness & 0.571 \\
\hline
\end{tabular}


According to Amabile [1], applying CAT interjudge reliability is equivalent to construct validity. In general, construct validity refers to whether a scale measures the construct that it purports to measure [24]. Assigned to CAT as well as to our case, this suggests that our scale has construct validity if it measures idea quality factually. However, the quality of creative ideas is always judged subjectively; in other words, quality of a creative idea is in the eye of the beholder. Thus, if a group of judges independently agrees that a given product is highly creative, then it can and must be accepted as such [1]. Hence, validity is given if all judges arrive at the same or nearly the same evaluations concerning each idea quality dimension. As it concerns the use of CAT, construct validity is given if our scale shows a sufficient degree of reliability. As this is the case, we assume that our idea measuring scale shows a sufficient degree of construct validity.

Finally, in order to express the degree of quality for each of the 61 evaluated ideas, we constructed a quality index reaching from 0 to 192 . Ideas reached quality scores between 23 and 113 . The mean value was 81.12. Kolmogorov-Smirnov test confirmed the normality of the distribution $(\mathrm{p}=0.088)$.

\subsection{Results}

In order to test the proposed hypotheses, a multiple regression analysis was employed. Regression analysis is a statistical tool concerned with evaluating the relationship between a dependent variable and one or more independent variables. The proposed research model in this study has one dependent variable (quality level of ideas) and six independent variables (motives Capability signaling, Fun, Altruism, Recognition, Product Improvement and Enhancement, and Learning). Summated scores of the respective motivation factors were used to obtain the scores for the independent measures; the quality indices of ideas (summated scores of the respective idea dimensions) were used to obtain the scores for the dependent measure. We considered 61 data sets in our regression analysis. Each data set contained the idea score of one of the evaluated 61 ideas, including the motivation survey answers of its corresponding idea contributors. The runs test, Levene's test, and Kolmogorov-Smirnov test were conducted to test for randomness, constancy of variance, and normality, respectively. These tests show that there is no evidence of violation of the assumptions underlying multiple regression analysis. Also, there is no evidence of multicollinearity of the independent variables. Independent variable VIFs range from 1.41 to 2.08 (see Table 6) and can be considered as acceptable, as they are under Belsley, Kuh, and Welsch's recommended level of $<4.00$ [5].

In order to test the goodness of fit of our underlying regression model, we checked the coefficient of determination (R2). An $\mathrm{R}^{2}$ of 0.549 (see Table 6) suggested adequate fit. Furthermore, we checked the goodness of fit of our model by conducting an f-test. The F-value was 10.960 (see table 6 ), well beyond the corresponding upper critical value of the $F$ distribution (2.27), which indicates an adequate fit as well.

The results of the multiple regression analysis (see Table 6) show that the motives: Capability signaling, Fun, and Recognition are significant predictors of idea quality. These findings support three hypotheses (H1, $\mathrm{H} 2$, and H4). On the other side our results show insufficient evidence for significant influence of the motives "Altruism" (H3) and "Product Improvement and Enhancement" (H5). Hypothesis (H6) was not supported, which do not mean that "Learning" is a significant predictor, in reverse. Further statistical methods (for example equivalence testing) have to be applied to prove if "Learning" is a predictor of idea quality.

Table 6: Results of regression analysis

\begin{tabular}{lccccc}
\hline Independent variable & t-Stat & p-value & VIF & $\begin{array}{c}\text { Hypothesis and } \\
\text { hypothesized effect }\end{array}$ & Supported? \\
\hline Capability Signaling & 2.867 & 0.006 & 2.08 & $\mathrm{H} 1+$ & Yes \\
\hline Fun & 2.754 & 0.008 & 1.41 & $\mathrm{H} 2+$ & Yes \\
\hline Altruism & -1.307 & 0.197 & 1.62 & $\mathrm{H} 3 \pm$ & Yes \\
\hline Recognition & 2.366 & 0.022 & 1.95 & $\mathrm{H} 4+$ & $\mathrm{Hes}$ \\
\hline Prod Imp + Enh & 1.506 & 0.138 & 1.66 & $\mathrm{H} 6 \pm$ & No \\
\hline Learning & -2.109 & 0.040 & 1.61 & & \\
\hline $\mathrm{R}^{2}=0.549$ & & & & \\
\hline $\begin{array}{l}\text { F-value }=10.960 \\
\text { corresponding upper critical value of the F distribution }=2.27 \text { (numerator df }=6 ; \text { denominator df }=54 \text { at } 5 \% \\
\text { significance level }\end{array}$
\end{tabular}




\section{Discussion}

In this research, the influence of individual motivations for participation in VCI on idea quality was studied in the context of the SAPiens Community. The main findings of our study are as follows: (1) Participants of VCI who are motivated by sending out capability signals through their ideas submit ideas of higher quality. (2) Participants of VCI who have fun in developing ideas submit ideas of higher quality. (3) Participants who are motivated by receiving recognition on the basis of their ideas submit ideas of higher quality. (4) Intrinsic motivation, as well as extrinsic motivation, influences idea quality, which can be seen as a result of creativity.

Regarding (4), claiming that intrinsic as well as extrinsic motivation is conducive to idea quality, our results go hand in hand with the latest understanding of the so-called Intrinsic Motivation Hypothesis, which is also known as Intrinsic Motivation Principle. In the 1980s, psychologists were convinced that solely intrinsic motivation is beneficial to creativity, such as drawing a picture or developing an idea. A lot of empirical work supports this proposition. For example, in a set of longitudinal studies following individuals from elementary school through adulthood, Torrance $[52,51,50]$ found that people who were doing what they loved (intrinsic motivation) were more creative in their pursuits. Another study of talented youth in math and science reported that these creative teens displayed higher levels of intrinsic motivation than did their peers [26].

Recently, a growing body of empirical studies has led to a revised understanding of this proposition. Several recent studies have revealed that extrinsic motivation in coexistence with intrinsic motivations influences a high level of creativity. For example, Amabile and Gryskiewicz [2], found that in workplaces evaluation or feedback that recognizes creative accomplishment can also be conducive to creativity. Additionally, Gruber's [21, 22] case studies of highly creative individuals suggest that eminent creators, such as Darwin or Newton, balanced intrinsic reasons for creating with some degree of extrinsic motivation that enabled them to sustain visions of revolutionizing the world's thinking. Our results confirmed this revised understanding of the Intrinsic Motivation Hypothesis. Our results thus contribute to a broader understanding of how motivations influence creativity.

Further, our results refer to insights from the Investment Theory of Creativity. Sternberg's and Lubart's Investment Theory of Creativity is an approach to describe creativity. According to this theory, creativity requires a confluence of six distinct but interrelated resources [48]. One of these is environment. Individuals need an environment that is supportive and rewarding of creative ideas. One could have all the internal resources needed to think creatively, but without some environmental support, such as a forum for proposing those ideas, a person's creativity might never be displayed. An important part of the environment is recognition of displayed creativity [48]; in other words, anticipated recognition by others represents a supportive environment in which creative ideas will grow. As we identified recognition as a major influencing factor of idea quality, our results contribute by confirming the body of knowledge regarding Sternberg's Investment Theory of Creativity.

\subsection{Implications for Practice}

We have shown evidence that certain extrinsic motivations are significant predictors of idea quality. As learned, extrinsic motivation is marked by a focus on getting rewards, such as recognition, learning knowledge, etc. Thus, knowing these motivations and carefully analyzing and understanding them is important, as it will provide valuable insights not only into how firms running VCI can harvest ideas of good quality from them, but also how they can create solid reward strategies in order to feed these motivations. This is highly relevant, as activating people who are encouraged by these extrinsic motivations will probably raise the number of high quality ideas in VCI.

\subsection{Limitations}

One of the major limitations of this study involves the sample of our survey. First, the sample size was relatively small. Despite the fact that the size was adequate for applied factor analysis, it is barely acceptable for applied regression analysis, suggesting that our results would have been more meaningful with a higher sample size. Future research should test and validate the model by collecting more data sets.

Furthermore, the motivation factors presented in this study are based on a review of prior literature. However, this study does not claim that a comprehensive, exhaustive list of factors has been identified. Future studies should extend our model by incorporating constructs that can supplement the model. 


\section{Appendix}

Table 7. Rotated component matrix

\begin{tabular}{|c|c|c|c|c|c|c|}
\hline \multirow{2}{*}{$\begin{array}{l}\text { Items } \\
\text { I submitted an idea to the SAPiens ideas community } \\
\text { because... }\end{array}$} & \multicolumn{6}{|c|}{ Components } \\
\hline & 1 & 2 & 3 & 4 & 5 & 6 \\
\hline \multicolumn{7}{|c|}{ 1. Fun } \\
\hline $\begin{array}{l}\text {... I have fun in working out ideas and creative } \\
\text { solutions. (1.1) }\end{array}$ & 0.065 & $\underline{0.660}$ & 0.268 & 0.065 & 0.117 & -0.039 \\
\hline $\begin{array}{l}\text {... I perceive composing creative ideas as a kind of self- } \\
\text { realization. (1.2) }\end{array}$ & 0.043 & $\underline{0.630}$ & 0.026 & 0.209 & 0.325 & 0.176 \\
\hline ... I take much pleasure in being creative. (1.3) & 0.255 & $\underline{0.785}$ & 0.203 & 0.107 & 0.118 & 0.030 \\
\hline \multicolumn{7}{|c|}{$\begin{array}{ll} & \text { Intellectual stimulation } \\
\end{array}$} \\
\hline ... I'm stimulated by generating creative ideas. (2.1) & \multicolumn{6}{|c|}{ excluded as item did not achieve critical MSA value } \\
\hline $\begin{array}{l}\text {.. I'm intellectually challenged by developing creative } \\
\text { ideas. (2.2) }\end{array}$ & 0.190 & $\underline{0.898}$ & 0.065 & -0.023 & 0.082 & 0.135 \\
\hline \multicolumn{7}{|l|}{ 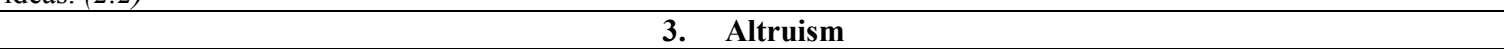 } \\
\hline ... I want to benefit others by contributing an idea. (3.1) & -0.106 & 0.360 & 0.569 & 0.203 & 0.300 & 0.141 \\
\hline $\begin{array}{l}\text {... I want to make my idea available to the general } \\
\text { public without expecting any return. (3.2) }\end{array}$ & 0.058 & 0.106 & $\underline{0.727}$ & 0.141 & -0.020 & 0.162 \\
\hline \multicolumn{7}{|c|}{ Reciprocity } \\
\hline $\begin{array}{l}\ldots \text { I believe that SAP has given time and effort to } \\
\text { developing the SAP software, so that I want to give back } \\
\text { my ideas to SAP. (4.1) }\end{array}$ & 0.024 & -0.050 & 0.468 & 0.161 & 0.261 & 0.508 \\
\hline $\begin{array}{l}\text {.. I want to reciprocate to SAP as I use the SAP } \\
\text { software gratis. (4.2) }\end{array}$ & \multicolumn{6}{|c|}{ excluded as item did not achieve critical MSA value } \\
\hline $\begin{array}{l}\text {.. I want to give SAP my ideas as I return professional } \\
\text { qualifications through SAP. (4.3) }\end{array}$ & \multicolumn{6}{|c|}{ excluded as item did not achieve critical MSA value } \\
\hline $\begin{array}{l}\ldots \text { I want to benefit SAP by submitting an idea, as I } \\
\text { have benefitted from my SAP skills. (4.4) }\end{array}$ & \multicolumn{6}{|c|}{ excluded as item did not achieve critical MSA value } \\
\hline \multicolumn{7}{|c|}{ Recognition } \\
\hline $\begin{array}{l}\text {... I hoped that other members would appreciate my } \\
\text { idea(s). (5.1) }\end{array}$ & 0.423 & 0.236 & 0.048 & $\underline{0.610}$ & 0.087 & 0.120 \\
\hline $\begin{array}{l}\text {... I hoped that other participants would honor my } \\
\text { idea(s). (5.2) }\end{array}$ & 0.110 & 0.452 & 0.407 & $\underline{0.418}$ & 0.096 & 0.006 \\
\hline ... I hoped that SAP would value my idea(s). (5.3) & 0.415 & 0.089 & 0.131 & $\underline{0.710}$ & 0.191 & 0.284 \\
\hline ... I hoped that SAP would appreciate my idea(s). (5.4) & 0.046 & 0.094 & 0.210 & $\overline{\mathbf{0 . 8 3 2}}$ & 0.253 & 0.071 \\
\hline \multicolumn{7}{|c|}{ 6. Capability Signaling } \\
\hline $\begin{array}{l}\text {... I hoped to show my skills and abilities through my } \\
\text { idea(s) to potential employers. (6.1) }\end{array}$ & 0.624 & 0.263 & -0.080 & 0.229 & 0.400 & -0.040 \\
\hline $\begin{array}{l}\ldots \text { I hoped to convince SAP of my skills and abilities } \\
\text { through my idea(s). (6.2) }\end{array}$ & $\underline{0.762}$ & 0.214 & -0.121 & 0.337 & 0.160 & 0.216 \\
\hline $\begin{array}{l}\text {.. I hoped to demonstrate my skills and abilities } \\
\text { through my idea(s). (6.3) }\end{array}$ & $\underline{\mathbf{0 . 8 5 3}}$ & 0.003 & 0.125 & 0.003 & 0.164 & 0.126 \\
\hline \multicolumn{7}{|c|}{ 7. Identification with the organizing firm } \\
\hline ... I identify with the SAP brand. (7.1) & 0.376 & 0.227 & 0.445 & 0.144 & 0.042 & 0.075 \\
\hline $\begin{array}{l}\ldots \text { I' } m \text { into SAP and because of that I want to support } \\
\text { SAP. (7.2) }\end{array}$ & 0.383 & 0.347 & $\underline{0.588}$ & -0.009 & 0.313 & 0.099 \\
\hline \multicolumn{7}{|c|}{ 8. Product improvement } \\
\hline $\begin{array}{l}\ldots \text { I wanted to give a helping hand in improving existing } \\
\text { SAP software. (8.1) }\end{array}$ & 0.042 & 0.069 & -0.023 & 0.164 & $\underline{0.644}$ & 0.183 \\
\hline $\begin{array}{l}\text {... I detected a software bug and I wanted to help fix it. } \\
\text { (8.2) }\end{array}$ & \multicolumn{6}{|c|}{ excluded as item did not achieve critical MSA value } \\
\hline \multicolumn{7}{|c|}{ 9. $\quad$ Need } \\
\hline $\begin{array}{l}\text {... my idea mirrored a need that was not covered by } \\
\text { existing SAP software applications, yet. (9.1) }\end{array}$ & 0.086 & 0.205 & 0.312 & 0.360 & $\underline{0.670}$ & -0.065 \\
\hline $\begin{array}{l}\ldots \text { I wished to tell SAP about my certain needs that were } \\
\text { not covered by existing SAP applications. (9.2) }\end{array}$ & 0.141 & 0.120 & 0.444 & -0.124 & $\underline{0.590}$ & -0.100 \\
\hline
\end{tabular}




\begin{tabular}{|c|c|c|c|c|c|c|}
\hline $\begin{array}{l}\text {.. I detected a need for a certain SAP software } \\
\text { application and put it into an idea. (9.3) }\end{array}$ & 0.129 & 0.364 & 0.024 & 0.194 & $\underline{0.578}$ & 0.110 \\
\hline \multicolumn{7}{|c|}{ 10. Learning } \\
\hline $\begin{array}{l}\text {.. I hoped to get learning experiences through the } \\
\text { feedback concerning my idea(s). (10.1) }\end{array}$ & 0.413 & 0.138 & 0.426 & -0.011 & -0.102 & $\underline{0.677}$ \\
\hline $\begin{array}{l}\text {... I hoped to learn from discussions with other members } \\
\text { of the SAPiens community. }(10.2)\end{array}$ & 0.244 & 0.158 & 0.041 & 0.202 & 0.131 & $\underline{0.785}$ \\
\hline \multicolumn{7}{|c|}{$\begin{array}{l}\text { 11. Peer-to-Peer Communication } \\
\end{array}$} \\
\hline $\begin{array}{l}\text {... I hoped to get in contact with other SAP software } \\
\text { users in order to talk with them about my idea(s). (11.1) }\end{array}$ & $\underline{0,644}$ & 0.107 & 0.285 & 0.124 & -0.099 & 0.231 \\
\hline $\begin{array}{l}\text {... I hoped to get in contact with other SAP software } \\
\text { users in order to share experiences and information. } \\
\text { (11.2) }\end{array}$ & 0.482 & 0.348 & 0.314 & 0.222 & -0293 & 0.057 \\
\hline Cronbach's Alpha & 0.857 & 0.860 & 0.772 & 0.852 & 0.779 & 0.804 \\
\hline $\begin{array}{l}\text { Factor Means (scale anchor } 1=\text { strongly disagree; } \\
5=\text { strongly agree) }\end{array}$ & 3.05 & 4.14 & 3.51 & 3.48 & 3.87 & 3.10 \\
\hline
\end{tabular}

\section{References}

[1] T. M. Amabile, Creativity in Context, Westview Press, Boulder, 1996.

[2] T. M. Amabile and N. Gryskiewicz, "The creative environment scales: The work environment inventory", Creativitiy Research Journal, 2 (1989), pp. 231-254.

[3] R. P. Bagozzi and Y. Yi, "On the evaluation of Structural Equatation Models", Journal of the Academy of Marketing Sciences, 16 (1988), pp. 74-94.

[4] H. Barki and A. Pinsonneault, "Small Group Brainstorming: Is Electronic Brainstorming the Most Effective Approach?", Small Group Research, 32 (2001), pp. 158-205.

[5] D. Belsley, E. Kuh and W. R., Regression Diagnostics, New York et al., 1980.

[6] C. Binnewies, S. Ohly and C. Niessen, "Age and Creativity at Work: The Interplay between Job Resources, Age, and Idea Creativity", Journal of Managerial Psychology, 23 (2008), pp. 438-457.

[7] R. Bogazzi, Y. Yi and L. Phillips, "Assessing Construct Validity in Organizational Research", Administrative Science Quarterly, 36 (1991), pp. 421-458.

[8] J. Bortz and N. Döring, Forschungsmethoden und Evaluation für Human- und Sozialwissenschaftler, Springer, Berlin, 2002.

[9] U. Bretschneider, Motivation for Participation in Ideas Competitions: Emprirical Insights from the SAPiens Case, in H. K. Arndt and H. Krcmar, eds., Very Large Business Applications (VLBA), Shaker Verlag, Aachen, 2009, pp. 124-138.
[10] M. W. Browne and R. Cudeck, Alternative ways of assessing model fit, in K. A. Bollen and J. S. Long, eds., Testing Structural Equation Models, Sage, Newbury Park, 1993.

[11] H. Chesbrough, "The era of open innovation", Sloan Management Review, 44 (2003), pp. 35-41.

[12] W. H. Cooper, R. B. Gallupe, S. Pollard and J. Cadsby, "Some Liberating Effects of Anonymous Electronic Brainstorming", Small Group Research, 29 (1998), pp. 147-178.

[13] E. E. Cureton and R. B. D'Agostino, Factor Analysis: An Applied Approach, Hillsdale, New Jersey, 1983.

[14] D. L. Dean, J. M. Hender, T. L. Rodgers and E. L. Santanen, "Identifying Quality, Novel, and Creative Ideas: Constructs and Scales for Idea Evaluation", Journal of the Association for Information Systems, 7 (2006), pp. 646699.

[15] E. L. Deci and R. M. Ryan, Intrinsic Motivation and Self-Determination in Human Behavior, Springer, Heidelberg, 1985.

[16] R. Eisenberger and L. Rhoades, "Incremental Effects of Reward on Creativity", Journal of Personality and Social Psychology, 81 (2001), pp. 728-741.

[17] C. Faure, "Beyond Brainstorming: The Effects of Different Group Procedures on Selection of Ideas and Satisfaction with the Process", Journal of Creative Behavior, 38 (2004), pp. 13-34.

[18] C. Fornell and D. F. Larcker, "Evaluating Structural Equation Models with Unobservable Variables and Measurement Error", Journal of Marketing Research, 18 (1981), pp. 39-50. 
[19] M. J. Garfield, J. T. Nolan, A. R. Dennis and J. W. Satzinger, "Modifying Paradigms-Individual Differences, Creativity Techniques, and Exposure to Ideas in Group Idea Generation", Information Systems Research, 12 (2001), pp. 322-333.

[20] J. M. George, "Creativity in organizations", Academy of Management Annuals, 1 (2007), pp. 439-477.

[21] H. E. Gruber, The self-construction of extraordinary, in R. J. Sternberg and J. E. Davidson, eds., Conceptions of Giftedness, Cambridge University Presss, Cambridge, 1986, pp. 247-263.

[22] H. E. Gruber and S. N. Davis, Inching our way up Mount Olympus: The evolving-systems approach to creative thinking, in R. J. Sternberg, ed., The Nature of Creativity, Cambridge University Press, Cambirdge, 1988, pp. 143-169.

[23] K. F. Habermeier, "Product Use and Product Improvement", Research Policy, 19 (1990), pp. 271-283.

[24] J. F. Hair, R. E. Anderson, R. L. Tatham and W. C. Black, Multivariate Data Analysis, Prentice-Hall, Upper Saddle River, NJ, 1998.

[25] A. Hars and S. Ou, "Working for free? Motivations for participating in open-source projects", International Journal of Electronic Commerce, 6 (2002), pp. 25-39.

[26] T. Heinzen, C. Mills and P. Cameron, "Scientific Innovation Potential", Creativitiy Research Journal, 6 (1993), pp. $261-269$.

[27] J. M. Hender, D. L. Dean, T. L. Rodgers and J. F. Nunamaker Jr., "An Examination of the Impact of Stimuli Type and GSS Structure on Creativity: Brainstorming vs. Nonbrainstorming Techniques in a GSS Environment", Journal of Management Information Systems, 18 (2002), pp. 59-85.

[28] F. Herzberg, The Managerial Choice, Olympus, Salt Lake City, 1982.

[29] B. Holmström, "Managerial Incentive Problems. A Dynamic Perspective", Review of Economic Studies, 66 (1999), pp. 169-182.

[30] C. Homburg and A. Giering, "Konzeptionalisierung und Operationalisierung komplexer Konstrukte: Ein Leitfaden für die Marketingforschung", Marketing Zeitschrift für Forschung und Praxis, 18 (1996), pp. 5-24.

[31] M. W. Kramer and C. L. Kuo, "The Impact of Brainstorming Techniques on Subsequent Group Processes", Small Group Research, 28 (1997), pp. 218-242.

[32] J. M. Leimeister, M. Huber, U. Bretschneider and H. Krcmar, "Leveraging Crowdsourcing: ActivationSupporting Components for IT-Based Ideas Competitions", Journal of Management Information Systems, 26 (2009), pp. 197-224.
[33] J. M. Leimeister, K. Schweizer, S. Leimeister and H. Krcmar, "Do virtual communities matter for the social support of patients? Antecedents and effects of virtual relationships in online communities.", Information Technology \& People, 21 (2008), pp. 350-374.

[34] K. R. MacCrimmon and C. Wagner, "Stimulating ideas through creative software", Management Science, 40 (1994), pp. 1514-1532.

[35] A. H. Maslow, Motivation and Personality, Harper, New York, 1987.

[36] B. Massetti, "An Empirical Examination of the Creativity Support Systems on Idea Generation", MIS Quarterly, 20 (1996), pp. 83-97.

[37] A. Miura and M. Hida, "Synergy Between Diversity and Similarity in Group Idea Generation", Small Group Research, 35 (2004), pp. 540-564.

[38] M. D. Mumford, "Tradeoffs Between Ideas and Structure: Individual Versus Group Performance in Creative Problem Solving", Journal of Creative Behavior, 35 (2001), pp. 1-23.

[39] S. Nambisan, "Designing virtual customer environments for new product development: toward a theory", Academy of Management Review, 27 (2002), pp. 392-413.

[40] J. C. Nunnally, Psychometric Theory, New York, 1978.

[41] J. Ozinga, Altruism, Praeger, Westport, CT, 1999.

[42] J. A. Plucker and J. S. Renzulli, Psychometric approaches to the study of human creativity, in R. J. Sternberg, ed., Handbook of Creativity, Cambridge University Press, Cambridge, 1999, pp. 35-61.

[43] R. E. Potter and P. Balthazard, "The Role Individual Memory and Attention Processes During Electronic Brainstorming", MIS Quarterly, 28 (2004), pp. 621-643.

[44] S. Rafaeli, T. Hayat and Y. Ariel, Knowledge Building and Motivations in Wikipedia: Participation as "Ba", in F. J. Ricardo, ed., Cyberculture and New Media, Rodopi, New York, 2009, pp. 52-69.

[45] C. E. Shalley, "Effects of Coaction, Expected Evaluation, and Goal Setting on Creativity and Productivity", 38, 2 (1995).

[46] C. E. Shalley, J. Zhou and G. R. Oldham, "The effects of personal and contextual characteristics on creativity: Where should we go from here?", Journal of Management, 30 (2004), pp. 933-958. 
[47] J. J. Sosik, B. J. Avolio and S. S. Kahai, "Effects of Leadership Style and Anonymity on Group Potency and Effectiveness in Group Decision Support System Environment", Journal of Applied Psychology, 82 (1997).

[48] R. J. Sternberg, "The nature of creativity", Creativity Research Journal, 18 (2006), pp. 87-98.

[49] S. G. Straus and J. E. McGrath, "Does Medium Matter? The Interaction of Task Type and Technology on Group Performance and Member Reactions", Journal of Applied Psychology, 79 (1994), pp. 87-97.

[50] E. P. Torrence, "Future career umage as a predictor of creative achievement in a 22-year longitudinal study", Psychological Reports, 60 (1987), pp. 574.

[51] E. P. Torrence, "The Importance of Falling in Love with "Something"'", Creative Child and Adult Quarterly, 8 (1983), pp. 72-78.

[52] E. P. Torrence, "Predicting the Creativity of Elementary School Children (1958-1980)", Gifted Child Quarterly, 25 (1981), pp. 55-62.

[53] J. S. Valacich, B. C. Wheeler, B. E. Mennecke and R. Wachter, "The Effects of Numerical and Logical Group Size on Computer-Mediated Idea Generation", Organizational Behavior and Human Decision Processes, 62 (1995), pp. 318-329. 